Clinical Medicine: Case Report

Poster

Abstract ID: 48

\title{
Post Herpetic Neuralgia After Acyclovir Treatment
}

\author{
Abdul Hadi Mohamed ${ }^{\mathrm{a}}$ | Mohd Shukrimi Awang ${ }^{\mathrm{b}}$ | Nor Zamzila Abdullah ${ }^{\mathrm{c}} \mid$ Mohd Basri Mat Nor $^{\mathrm{a}}$ \\ ${ }^{a}$ Department of Anaesthesiology and Intensive Care, Kulliyyah of Medicine, International Islamic \\ University Malaysia \\ ${ }^{b}$ Department of Orthopaedics, Traumatology \& Rehabilitation, Kulliyyah of Medicine, International \\ Islamic University Malaysia \\ 'Department of Basic Medical Sciences, Kulliyyah of Medicine, International Islamic University \\ Malaysia
}

Post Herpetic Neuralgia (PHN) is often diagnosed when pain persists in a dermatomal pattern weeks after the herpes zoster vesicular eruption has healed. There is a definite tendency for PHN to improve with time. There is no way of predicting who will recover. However, some reported that as many as $40 \%$ of patients with PHN will continue to have long-term problems because of incomplete or no pain despite the best treatments given. This retrospective series discussed the outcome of treatment of 3 patients with PHN, using acyclovir, Gabapentin and analgesics. Patients were treated by a single pain specialist in a conventional community pain practice. Therapies were given twice-monthly for 1-2 months, then less frequently until pain relief was optimized. Patients received a median of 7 treatments (range 4 -11). Median baseline allodynia levels were reduced from $9 / 10$ (range 8 to 10 ) to $0 / 10$ (range 0 to 6 ), intermittent shooting pain from $9 / 10$ (range 8 to 10) to $0 / 10$ (range 0 to 6 ). 1 of 3 patients (30\%) was able to be weaned off pain medications. These data showed that there is variation in the response to treatment in patients suffering from PHN. The response ranged from a complete cure to unresponsive at all to the treatment given. There is no way of predicting who will fully recover.

KEYWORDS: herpes zoster, acyclovir, post herpetic neuralgia, gabapentin 